\title{
Characterization of the preferences towards jalapeño peppers from the perspective of the Sonoran consumers
}

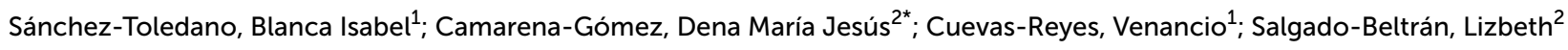 \\ ${ }^{1}$ Instituto Nacional de Investigaciones Forestales, Agrícolas y Pecuarias; ${ }^{2}$ Universidad de Sonora, \\ División de Ciencias Económicas y Administrativas. \\ *Corresponding Author: dena.camarena@unison.mx
}

\begin{abstract}
Objective: To assess the Sonoran (Mexico) consumer perspective regard their buying habits, consumption and the attitudes and attributes they most valued from jalapeño pepper.

Design/Methodology/Approach: The assessment took place in three phases. The first consisted of the design of a questionnaire, the second its application to a sample of $n=200$ consumers and finally univariate (means and modes) and bivariate (Chi-square) analyzes on the obtained data.

Results: The flavor is a key element in the consumption of jalapeño peppers. There is a tendency towards frequent consumption, although the portions are measured since they are usually less than $0.5 \mathrm{~kg}$. It was identified that for the consumer it is important no damage or browning is visible on the external appearance of the peppers, and that they prefer peppers of a dark green color over another coloring. Specifically, there is a willingness to pay between $\$ 0.5$ and $\$ 1.0$ US per kilogram. The frequent consumers of jalapeño pepper are under 40 years old, accentuated in the 18 to 24 years old segment, with medium income level. In this segment, there is the preference for aroma and hotness (pungency) that the chili peppers have.
\end{abstract}

Study limitations/implications: This study is limited to consumers from the northwestern region of Mexico. The obtained information provides guidelines to deepen the knowledge of this product from their market perspective. The added-value strategies should be aimed to increase the external quality of the product.

Keywords: attributes of chili peppers, expressed preferences, consumer.

\section{INTRODUCCIÓN}

Mexic is one of the main producing countries of chili peppers (Capsicum annuum L.), with a production MeXICO of just over three million tons, it occupies the second position in the world (FAOSTAT, 2020). In its national context, this crop has a planted area of 152 thousand hectares and a production value of 32 million pesos (SIAP, 2019). Even when the production data is positive, various problems inhibit its production in the country, highlighting the costs of its inputs, their poor marketing, poor production organization, insufficient credits, and the lack of added value, among others (Galindo, 2007).
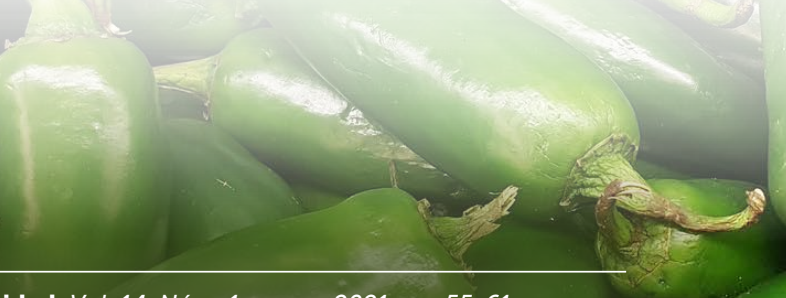

Agroproductividad: Vol. 14, Núm. 1, enero. 2021. pp: 55-61. Recibido: mayo, 2020. Aceptado: enero, 2021. 
The diversity of peppers is wide, there are more than a hundred varieties nationwide, concentrated in 22 groups of green peppers and 12 for dried peppers. In the former, the jalapeño pepper (Capsicum annuum L.) stands out, it represents a third $(31.0 \%)$ of the national production. Except for Aguascalientes, the jalapeño pepper is grown throughout the country. The main producers are the states of Chihuahua (32.3\%), Sinaloa (17.5\%), Zacatecas (13.5\%) and San Luis Potosí (9.8\%), which together produce $73.1 \%$ of the national harvest (SIAP, 2019). In the case of Sonora, the registered production volumes have positioned it among the top ten pepper producing states at the national level, and is third in importance in the northwest of the country. According to the national agricultural planning 2017-2030 (SAGARPA, 2017), the state of Sonora is located between the strategic and historical regions in the production of jalapeño pepper, having an annual production increase of $2.61 \%$ in the last three years. In such a way that it went from 187,470 t in 2017 to 192,365 t in 2019 (SIAP, 2020). The production of green peppers that takes place in the state is of five types: bellpepper of export, in a greenhouse for export, open field, greenhouse, shade mesh and shade mesh for export, with a production of 94,380 t which represents $50.3 \%$ of the total of varieties; these are followed by jalapeño pepper sown in open field, for export and shade mesh with a production of 59,351 t (31.7\%); Anaheim peppers in open field, export and shade mesh with 24,451 t (13.0\%); serrano pepper for export and open field with a production of 9,008 t (4.8\%) and open field poblano pepper with 280 t of production (0.1\%) (SIAP, 2018). These figures suggest that there is significant potential for the positioning of jalapeño pepper, both in terms of its production and market. Despite these indicators, it must be considered that the market is highly competitive and the consumers can access a wide variety of green peppers. According to Pindyck and Rebinfield (2001), consumers allocate their income to the acquisition of different goods and services to maximize their well-being. In this process, some of the important variables are the price of goods and income. These variables limit the amount of purchase by the consumers; although other socioeconomic variables act as demand shifters that affect the number of purchased goods. Although several studies address the agronomic production process of jalapeño pepper (Pire and Pereira, 2018; Ramírez et al., 2017; Beltrán et al., 2016 inter alia), respect the demand and research on market behavior information is scarce, even more so when it comes to northwest Mexico (Pérez et al., 2017; Mejía et al., 2020).
To learn about this market, different aspects must be considered, such as the customers' expectations (Lupin and Rodriguez 2009). At the same time, it should be considered that there is no uniform consumer, but due to the changes in social and personal values, consumer preferences are also permanently changing (Schreiner et al., 2013)

In this regard, consumer-oriented studies have found that for peppers, color was a relevant characteristic for their acquisition among consumers in the state of Alabama, United States (Frank et al., 2001). In addition, for certain types of chili peppers, such as the "piquin" pepper (Capsicum annuum L. var. Glabriusculum), their taste encourages consumers to pay a higher price compared to serrano or jalapeño peppers (Villalón-Mendoza et al., 2016). Meanwhile, in products such as tomatoes, it has been identified that the availability of product "fresh" affects its purchasing behavior; that is, they are acquired when available, even during periods of scarcity within a year (Adeoye et al., 2015). Therefore, and due to the importance of the consumption of jalapeño pepper in the population, it was considered necessary to carry out a study to characterize the consumers of this vegetable, in aspects such as the type of product they demand and the characteristics they prefer. The main objective of this research was to assess, from the perspective of the Sonoran consumer, their buying and consuming habits for jalapeño pepper, as well as the attitudes and attributes that they most value of this product to contribute to its state of knowledge from a market perspective.

\section{MATERIALS AND METHODS}

To achieve the main objective, an empirical investigation was carried out at the city of Hermosillo, Sonora, which has 884,273 inhabitants and is located in the northwest area of Mexico (INEGI, 2015). The study was carried out in three phases, the first one consisted of the design of a questionnaire aimed at consumers. The survey was pretested to reduce errors and provide an understanding of the variables. For the sample size, a probability sampling was applied, using the infinite population formula and a simple random sampling was calculated with a $7 \%$ error, obtaining a sample size of $n=200$ surveys. In the second phase, the fieldwork was carried out. The people who responded to the survey were 18 years of age or older and received no monetary compensation for their participation. The information was collected in January and February 2020. For the third phase of the research, a database was developed in the IBM SPSS 20 software. To 
perform the analysis of the information, we proceeded to identify the type of measurement scale used in each question. The methods used for the data analysis were two: univariate (means and modes) and bivariate (Chisquare).

\section{RESULTS AND DISCUSSION}

The obtained results show that most of the participants were women (52\%), whose recurring occupations were as administrative staff (29.5\%), followed by students and houseworkers, with 16.5 and $15 \%$ respectively. The largest proportion of those surveyed has university studies (59\%) and high school (26\%). The most represented age ranged from 18 to 34 years (52\%), followed by those over 60 (10\%). The most common incomes range from 5 to 10 thousand pesos per month (33\%), as well as between 10 to 15 thousand pesos (28.5\%), while the greater than 20 thousand pesos per month income range proportion was significantly lower (4\%). An implicit condition for participating in the study is that the respondents were jalapeño pepper consumers.

According to the data, it was observed that out of the different ways in which they can be tasted, the processed peppers option stands out as the most common (59.5\%), followed by fresh peppers (39\%), then dry or smoked (1.5\%). Among the reasons for consumption, the flavor is the most prominent (44.8\%), as well as their multifunctionality in its uses (18.5\%) or the amount of hotness (pungency) they have (14.2\%). Other related aspects such as aroma, color, nutritional value, among others, presented less incidence in the causes for choice among consumers (Table 1).

Regard the consumption frequency, those that consume "some days" during the week prevailed with $51.5 \%$ of the total, followed by those that consume it daily, from Monday to Friday (20\%). Also, weekend consumers were recorded $(15 \%)$ and less than once a month consumer (13.5\%). The most frequent consumption, $78.5 \%$ of the cases, were of less than $0.5 \mathrm{~kg}$, and $19.0 \%$ consumed between 0.5 $\mathrm{kg}$ and $1.0 \mathrm{~kg}$, while higher consumption was registered to a lesser extent (2.5\%). These results indicated that there is a tendency towards frequent consumption over occasional consumption and that the portions consumed are less than half a kilo (Table 2).

Regard the attributes of the jalapeño pepper that are most important to consumers, it is to be noted that according to the mean scores, considering a five-point Likert scale where 5 is in total agreement, the absence of physiological damage is the most important attribute for consumers, with an average value of 4.44 (Table 4). Another was the absence of injuries or damage on the product (4.35), while the external color, the degree of hotness and consistency were also revealed as highly valued attributes by consumers with mean scores of 4.03 in the first two and of 4.01 at last. With values above the average but lower than the main attributes, the size (3.87), the shape of the pepper (3.65), aroma (3.57) and width (3.47 and 3.04, respectively) (Table 3).

From the different characteristics that jalapeño peppers can have, the preferred color for $90 \%$ of consumers was a bright dark emerald green, other options such as medium yellow and orange-red were significantly less chosen, with 5.5 and $4.5 \%$ respectively. Regarding size, the preference for medium-size jalapeño peppers (64.5\%) prevailed, which ranged from 5 to $7.5 \mathrm{~cm}$. The most recurrent desired consistency was of high to the touch $(53 \%)$, while the preferred width of the fruit was medium (66\%), with a weight of 25 to $30 \mathrm{~g}(70 \%)$, while the most sought-after "striped" (physiologically mature) registered $69.5 \%$ of consumers (Table 4 ).

sumer $(13.5 \%)$. The

\begin{tabular}{|c|c|c|c|}
\hline Consumption & Sample (\%) & Consumption amount & Sample (\%) \\
\hline Dailye (Monday - Friday) & 20.0 & Less than $0.5 \mathrm{~kg}$ & 78.5 \\
\hline Some days during the week & 51.5 & From $0.5 \mathrm{~kg}$ to $1 \mathrm{~kg}$ & 19.0 \\
\hline Weekends & 15.0 & From 1 kg to 2 kg & 2.5 \\
\hline Less than once a month & 13.5 & & \\
\hline
\end{tabular}

\begin{tabular}{|c|c|c|c|c|c|}
\hline Characteristics & Sample (\%) & Characteristics & Sample (\%) & Characteristics & Sample (\%) \\
\hline Flavor & 44.8 & Spicy & 14.2 & $\begin{array}{l}\text { Other (nutritional, easy to get, } \\
\text { is what is given) }\end{array}$ & 7.6 \\
\hline Multifunctionality in its uses & 18.5 & Aroma & 7.9 & Mildly spicy & 7.0 \\
\hline
\end{tabular}


Table 3. Average scores regard jalapeño pepper attributes.

\begin{tabular}{|c|c|c|c|c|c|}
\hline Attributes & $\begin{array}{c}\text { Average } \\
\text { values }\end{array}$ & Attributes & $\begin{array}{c}\text { Average } \\
\text { values }\end{array}$ & Attributes & $\begin{array}{c}\text { Average } \\
\text { values }\end{array}$ \\
\hline The absence of physiological damage & 4.44 & Product consistency & 4.01 & Odor & 3.57 \\
\hline External color & 4.03 & Jalapeño peppershape & 3.65 & Weight & 3.04 \\
\hline The degree of pungency of the jalapeño pepper & 4.03 & & & Jalapeño pepper lines & 2.92 \\
\hline
\end{tabular}

\begin{tabular}{|c|c|c|c|}
\hline Color & Sample (\%) & Width & Sample (\%) \\
\hline Brilliant dark emerald green & 90.0 & Medium (3.0 a $3.5 \mathrm{~cm})$ & 66.0 \\
\hline Middle yellow & 5.5 & Big $(3.5$ a $4.0 \mathrm{~cm})$ & 31.5 \\
\hline Orange red & 4.5 & Jumbo (3.7 a $4.5 \mathrm{~cm})$ & 2.0 \\
\hline \multicolumn{2}{|l|}{ Size } & \multicolumn{2}{|c|}{ Line } \\
\hline Medium (5 a $7.5 \mathrm{~cm}$ ) & 64.5 & 0 al $10 \%$ & 69.5 \\
\hline Big $(8$ a $10 \mathrm{~cm})$ & 33.5 & De 10 a $15 \%$ & 27.0 \\
\hline Jumbo ( $\geq 10 \mathrm{~cm})$ & 2.0 & Más de $20 \%$ & 3.5 \\
\hline \multicolumn{2}{|l|}{ Consistence } & \multicolumn{2}{|c|}{ Weight } \\
\hline Medium consistency and to a lesser degree to the touch & 38.5 & 25 a $30 \mathrm{gr}$ & 70.0 \\
\hline High consistency to the touch & 53.0 & 30 a $45 \mathrm{gr}$ & 26.5 \\
\hline Consistency extremely high to the touch & 8.0 & 45 a $60 \mathrm{gr}$ & 0.5 \\
\hline
\end{tabular}

Regard the willingness to pay for jalapeño peppers, $42 \%$ of consumers consider that a value between $\$ 0.5$ to $\$ 0.75$ US per $\mathrm{kg}$ was adequate to promote their consumption, followed by $\$ 0.75$ to $\$ 1.25$ US per $\mathrm{kg}$ (34.5\%). Other values at the lower and upper end of the price were less viable options according to the consumers.

The results obtained with the Chi-square test (Table 5) showed that there is a positive association between the frequency of consumption and the sociodemographic and economic characters so that in the daily consumption the proportion of consumers is higher $(2 \%)$ compared to other options. When consumption is carried out on some days during the week, the trend is focused on young people age 18 to 24 (11\%), while consumption on weekends and sporadic consumption takes place less than once a month, it has a higher in the 25 to 29 years segment, in the first case (5\%) and 30 to 34 years in the second $(4.5 \%)$. It is also noted that the college degree is more frequent in any of the consumption frequencies and that the proportion of people who consume several times a week have a higher income than $\$ 1,500$ USD per month, accentuating in the range between \$250 and \$500 US, while occasional jalapeño pepper consumers represent a slight trend towards higher income.
In the correlation analyses, it was observed that there is a positive association between the type of consumption of pepper to the frequency of consumption (Table 6), in such a way that processed and fresh peppers are more commonly consumed among the people who taste it in the range of some days per week (29 and 21\% in each case). Likewise, the aroma and strong hotness are reasons for its consumption, especially among those who eat it often, either daily (75.5 and $7.5 \%)$ or some days during the week (6.5 and $13 \%$ ). It was also observed that consumption quantities of less than half a kilogram are more accentuated in those who consume it some days per week (44\%), followed to a lesser extent by sporadic consumers (13.5\%). Consumption in portions greater than half a kilogram is more prevalent among those who consume jalapeño peppers daily. At the same time, it is noted that in $37 \%$ of the cases, those who consume jalapeño peppers several times during the week have up to three members in their family who also consume the product. This trend decreases to $14 \%$ when four to six members consume jalapeño peppers in a homestead.

Regard their attributes, it was observed that it is appreciated by 23 and 10.5\% of consumers for being moderately spicy, particularly for those who consume it several days 
Table 5. Description of the obtained segments based on the consumption frequencies of jalapeño pepper and their socio-demographic and economic characteristics.

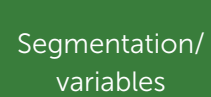

Segmentation/
variables
Chi-square Test

$\times 2$

(Probability value)
Frequency of consumption (\%)

Some days

of the week $(\mathrm{N}=103)$
Weekends $(\mathrm{N}=30)$
At least once a month $(\mathrm{N}=27)$
Age

\begin{tabular}{l|}
\hline $18-24$ \\
\hline $25-29$ \\
\hline $30-34$ \\
\hline $35-39$ \\
\hline $40-44$ \\
\hline $45-49$ \\
\hline $50-54$ \\
\hline $55-59$ \\
\hline 260
\end{tabular}

Study level

\begin{tabular}{l} 
Up to primary \\
\hline Secondary \\
\hline High school \\
\hline Bachelor degree \\
Higher (Master degree and PhD)
\end{tabular}

Monthly income level

$\leq 5$ thousand mexican pesos

5-10 thousand mexican pesos

10001-15 thousand mexican pesos

15001-20 thousand mexican pesos

20001-30 thousand mexican pesos

$\geq 30$ thousand mexican pesos

\begin{tabular}{|c|c|c|c|c}
\hline \multirow{4}{*}{} & 4.5 & 11.0 & 1.5 & 2.5 \\
\cline { 2 - 5 } & 2.5 & 8.5 & 5.0 & 2.0 \\
\cline { 2 - 5 } & 3.0 & 4.5 & 2.5 & 4.5 \\
\cline { 2 - 5 } & 1.5 & 6.0 & 0.0 & 0.5 \\
\cline { 2 - 5 } & 1.0 & 5.5 & 2.0 & 0.5 \\
\cline { 2 - 5 } & 0.5 & 6.0 & 0.5 & 0.5 \\
\cline { 2 - 5 } & 2.5 & 3.0 & 1.5 & 0.5 \\
\cline { 2 - 5 } & 2.5 & 1.0 & 0.5 & 1.5 \\
\hline
\end{tabular}

\begin{tabular}{|c|r|r|r|r}
\hline \multirow{3}{*}{$0.82^{* \star}$} & 0.5 & 0.5 & 0.5 & 0.0 \\
\cline { 2 - 5 } & 1.5 & 3.0 & 0.0 & 0.5 \\
\cline { 2 - 5 } & 7.5 & 15.5 & 2.0 & 1.0 \\
\cline { 2 - 5 } & 9.5 & 29.5 & 10.0 & 10.0 \\
\cline { 2 - 5 } & 1.0 & 3.0 & 2.5 & 2.0 \\
\hline
\end{tabular}

(n)

\begin{tabular}{|l|l|l|l}
\hline 4.0 & 12.0 & 1.0 & 2.0 \\
\hline 4.0 & 19.5 & 6.5 & 3.0 \\
\hline 7.0 & 13.0 & 3.0 & 5.5 \\
\hline 4.0 & 5.0 & 4.0 & 2.5 \\
\hline 1.0 & 2.0 & 0.0 & 0.0 \\
\hline 0.0 & 0.0 & 0.5 & 0.5 \\
\hline
\end{tabular}

a week and sporadic ones who do so once a month. "striped" peppers are more accepted in the lower limits of 0 to $10 \%$ in $41 \%$ of frequent consumers, compared to $10.5 \%$ of weekend consumers. For their part, $3 \%$ of those who consume jalapeño peppers daily consider that there are problems with their packaging. When considering other alternatives to consume jalapeño peppers, $17.5 \%$ of the regular consumers consider that incorporated in cheeses is another product where they like to consume it. Finally, it is noted that the bell or brown chili is a viable substitute for all consumers, but more so for those who consume several times a week (11.5\%), on weekends (5\%) and at least once a month (4\%).

\section{CONCLUSIONS}

These findings show that for the Sonoran consumers, the taste is a key element for the consumption of jalapeño peppers, there is a trend towards frequent consumption, although measured portions since they are usually less than half a kilogram. For the consumers, it is important that the external appearance of the peppers does not show damage and that they prefer the chili in a dark green color over other presentations. There is a marked trend towards medium size, weight and width, with slight "stripes" less than 10\%. Likewise, it is noted that there is an intermediate willingness to pay in ranges between $\$ 0.5$ and $\$ 1.0$ US per kilogram. On other hand, frequent consumers of jalapeño peppers are under 40 years of age, accentuated in segments from 18 to 24 years of age, with a mediumincome level. In this segment, there is a preference for the aroma and hotness of the pepper. The jalapeño pepper consumer preferences show some guidelines that can be useful when establishing production and commercial guidelines. Added-value strategies can be aimed at increasing the external quality of the product. 
Table 6. Description of the segments obtained based on the motivations and preferences of consumption towards jalapeño peppers.

\begin{tabular}{|c|c|c|c|c|c|}
\hline \multirow[b]{2}{*}{$\begin{array}{l}\text { Segmentation/ } \\
\text { variables }\end{array}$} & \multirow[b]{2}{*}{$\begin{array}{c}\text { Chi-square Test } \\
\text { X2 } \\
\text { (Probability value) }\end{array}$} & \multicolumn{4}{|c|}{ Frequency of consumption (\%) } \\
\hline & & $\begin{array}{c}\text { Daily } \\
\text { L-V } \\
(\mathrm{N}=40)\end{array}$ & $\begin{array}{l}\text { Some days } \\
\text { of the week } \\
(\mathrm{N}=103)\end{array}$ & $\begin{array}{l}\text { Weekends } \\
(\mathrm{N}=30)\end{array}$ & $\begin{array}{l}\text { At least once a } \\
\text { month }(\mathrm{N}=27)\end{array}$ \\
\hline
\end{tabular}

\section{Mode of consumption}

Consume the jalapeño pepper dried or smoked

Consume the processed jalapeño pepper

$0.011^{*}$

\begin{tabular}{|r|r|r|r|}
\hline 0.0 & 1.5 & 0.0 & 0.0 \\
\hline 9.0 & 29.0 & 9.5 & 12.0 \\
\hline 11.0 & 21.0 & 5.5 & 1.5 \\
\hline
\end{tabular}

Consume fresh jalapeño pepper

\section{Consumption reasons}

Consume because of the fragance

Consume for the spicy

$0.006 *$

$0.017^{*}$

5.5
7.5

$\mid$

6.5

13.0

0.0

\section{Consumption per week}

From 1 to 2 kilogram

From half to 1 kilogram

$0.000 *$

Less of half kilogram

\section{Family that consume it}

More than 9 members

7 to 9 members

4 to 6 members

1 to 3 members

\begin{tabular}{|r|r|r|r|}
\hline 1.5 & 0.5 & 0.5 & 0.0 \\
\hline 9.5 & 7.0 & 2.5 & 0.0 \\
\hline 9.0 & 44.0 & 12.0 & 13.5 \\
\hline
\end{tabular}

\section{Attributes that are valued}

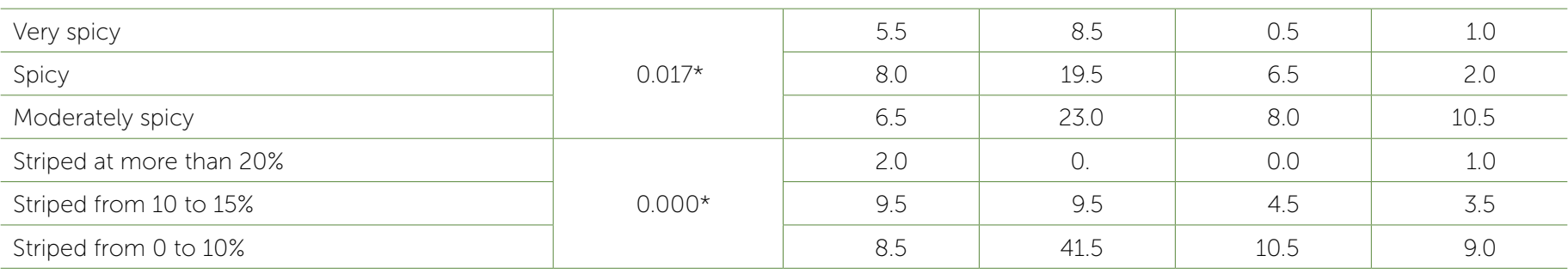

\section{Problems and sustitutes}

\begin{tabular}{|c|c|c|c|c|c|}
\hline Packaging problem & $0.069 * *$ & 3.0 & 2.5 & 1.0 & 2.5 \\
\hline Consume in cheeses & $0.010^{*}$ & 1.5 & 17.5 & 5.5 & 4.5 \\
\hline Bell or brown sustitutes & $0.094^{* *}$ & 2.0 & 11.5 & 5.0 & 4.0 \\
\hline
\end{tabular}

\section{REFERENCES}

Adeoye, IB, Adegbite, OO, Fashogbon, AE \& Layade, AA. (2016) Consumer Purchasing Behavior for Tomatoes, International Journal of Vegetable Science, 22:3, 259-265. DOl: 10.1080/19315260.2015.1028695

Beltrán-Morales, F. A., García-Hernández, J. L., Ruiz-Espinoza, F. H., Valdez-Cepeda, R. D., Preciado-Rangel, P., Fortis-Hernández, M., \& González-Zamora, A. (2016). Efecto de sustratos orgánicos en el crecimiento de seis variedades de chile jalapeño (Capsicum annuum L.). Ecosistemas y recursos agropecuarios, 3(7), 143-149.

Frank, C. A., Nelson, R. G., Simonne, E. H., Behe, B. K., \& Simonne, A. H. (2001). Consumer Preferences for Color, Price, and Vitamin C Content of Bell Peppers, HortScienceHortSci, 36(4), 795-800.

Galindo G., G. (2007). El servicio de asistencia técnica a los productores de chile seco en Zacatecas. Convergencia. Revista de Ciencias Sociales. 14 (43): 137-165.
INEGI (2015). Información por entidad, número de habitantes. Recuperado en julio de 2020 de: http://www.cuentame.inegi. org. $\mathrm{mx} / \mathrm{monografias/informacion/Son/Poblacion/default.}$ aspx?tema $=$ ME\&e $=26$

Lupin B. y Rodriguez MEM. (2009). El consumo de hortalizasorgánicas atributosvalorados de calidad. FACES: revista de la Facultad de Ciencias Económicas y Sociales, 15 (32); 25-47.

Mejía, V. S., Alcudia, G. M., \& Gómez, C. A. P. (2020). Preferencias de consumidores de salsas picantes guasalzas de comalcalco, tabasco. Hitos de ciencias económico administrativas, 25(73), 390-402

Pérez, R., Morales, J., López, H., \& Ayala, A. V. (2017). Intención de compra del consumidor organizacional de chile regional en el estado de Puebla, México. Agricultura, sociedad y desarrollo, 14(4), 599-615.

Pindyck, R. S. y L. Rubinfeld. (2001). Microeconomía. España, Quinta edición, Pearson-Prentice Hall. 
Pire, R., \& Pereira, A. (2018). Tamaño de los poros del suelo y crecimiento de raíz y vástago del chile jalapeño (Capsicum annuum L.). Agrociencia, 52(5), 685-693

Ramírez, J. A., Troyo, E., Preciado, P., Fortis, M., Gallegos, M. Á., Vázquez-z, \& García, J. L. (2017). Diagnóstico de nutrimento compuesto e interacciones nutrimentales en chile Jalapeño (Capsicum annuum L.) en suelos semiáridos. Ecosistemas y recursos agropecuarios, 4(11), 233 242.

SAGARPA. (2017). Planeación Agrícola Nacional 2017-2030, Chiles y pimientos Mexicanos. Recuperado en julio de 2020 de: https://www.gob.mx/cms/uploads/attachment/file/257072/PotencialChiles_y_Pimientos-parte_uno.pdf

Schreiner, M., Korn, M., Stenger, M., Holzgreve, L., \& Altmann, M. (2013). Current understanding and use of quality characteristics of horticulture products. Scientia Horticulturae 163: 63-69.

SIAP. (2018). Anuario estadístico de la producción agrícola: Sonora Anuario estadístico de la producción agricola: http://nube.siap.gob.mx/ (consultado 14 de julio 2020).

SIAP. (2019). Anuario estadístico de la producción agrícola: producción agrícola: http://nube.siap.gob. mx/cierre-agricola/(consultado 14 de julio 2020)

Villalón-Mendoza, H.,M. Ramirez-Meraz, F. Garza-Ocanas, \& R. Maiti. (2016). Value chain of Chile Piquin Wild Chili (Capsicum annuum L. var. glabriusculum) from Northeastern Mexico. Intl.J. BioResource Stress Mgt. 7(3):455-460.

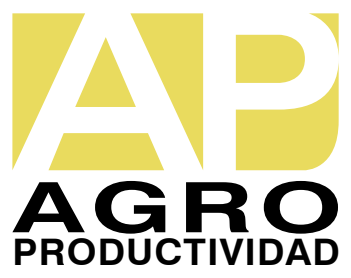

